\title{
CRISIS Y DESDEMOCRATIZACIÓN: POLÍTICA Y ECONOMÍA DE LA CRISIS BRASILEÑA
}

\section{CRISIS AND DE-DEMOCRATIZATION: POLITICS AND ECONOMY OF THE BRAZILIAN CRISIS}

\section{Guillermo Antonio Navarro Alvarado*}

\begin{abstract}
RESUMEN
El siguiente artículo tiene como objetivo exponer las variables generales de la crisis económico-política brasileña, iniciada en el año 2013 y vigente en la actualidad. Se pretenden exponer y analizar: a) las diversas corrientes interpretativas de la crisis; b) las estructuras históricas de poder político y su marco institucional; c) las determinantes estructurales de la crisis económica y las contradicciones político-económicas del modelo social-desarrollista. El análisis concluye que la crisis actual obedece a una dinámica multidimensional y es el producto de la profundización de las contradicciones estructurales e institucionales implicadas en un pacto democratizador inconcluso, que devino en un proceso de desdemocratización.
\end{abstract}

PALABRAS CLAVE: BRASIL * DEMOCRACIA * DEPENDENCIA * DESARROLLISMO * NEOLIBERALISMO

\section{ABSTRACT}

The following article aims to expose the general variables of the Brazilian economicpolitical crisis, which began in 2013 and is currently in force. The aim is to expose and analyze: a) the different interpretive aspects of the crisis; b) the historical structures of political power and their institutional framework; c) the structural determinants of the economic crisis and the political-economic contradictions of the Social-developmentalist model. The analysis concludes that the current crisis obeys to a multidimensional dynamic and is the product of the deepening structural and institutional contradictions implied in an inconclusive democratizing pact, which became a process of de-democratization.

KEYWORDS: BRAZIL * DEMOCRACY * DEPENDENCY * DEVELOPMENTALISM * NEOLIBERALISM 


\section{INTRODUCCIÓN}

A partir del año 2013, el proceso político-democrático brasileño experimenta el despliegue de una crisis profunda, expresada en el año 2016 por el proceso de impeachment (impedimento) de la expresidenta Dilma Rousseff y por la desarticulación estructurada del proyecto político-económico social-desarrollista, impulsado por el Partido de los Trabajadores ${ }^{1}$ (РT). Este periodo comprende desde 2003, con los sucesivos gobiernos de Luiz Ignacio Lula da Silva (2003-2010) y Dilma Vana Rousseff (2011-2016).

Este proceso se extiende a las formas de sociabilidad y reorganización del sistema político brasileño y a la restructuración hegemónica de las relaciones económico-políticas en el país, en el seno de un proceso de reorganización del espacio político institucional, la articulación de nuevas hegemonías y la modificación del contexto político latinoamericano e internacional. El proceso experimentado perfila una crisis extendida a diversas dimensiones de las relaciones políticas, sociales y de producción, que está transformando los marcos institucionales de los derechos sociales $y$ políticos conquistados por las clases trabajadoras brasileñas y constitucionalizados en el pacto democrático de 1988.

Este articulo desarrollará el análisis de los fenómenos que alimentan la crisis en diversas dimensiones del conjunto de la nación brasileña, proponiendo como ejes temáticos: a) los diversos marcos interpretativos de la crisis, sus debates y críticas; b) las estructuras históricas de poder político, entendidas estas en su clave político-económica, retomando las características particulares del proceso de democratización brasileña, que desde finales de la década del 80 caracteriza las instituciones sociales y políticas, en lo que se llamará un proceso "incompleto de transición" y las condiciones de posibilidad histórico-sociales y económicas del proyecto político petista ${ }^{2}$; y c) a la luz de esta caracterización general histórica, se pretende exponer

$1 \quad$ Partido dos Trabalhadores.

2 Se refiere al Partido de los Trabajadores (PT). los elementos generales del proyecto políticoeconómico petista, los alcances y los límites de su política económica, el social-desarrollismo, y las características estructurales que facilitaron la desaceleración económica, la crisis y la restauración neoliberal como hegemonía política.

\section{INTERPRETACIONES DE LA CRISIS: ¿CRISIS EPISÓDICA O CRISIS ESTRUCTURAL?}

En este contexto, la llamada crisis ha sido interpretada desde dos grandes perspectivas con acentos dimensionales, la primera como episódica-coyuntural y la segunda como estructural-histórica. En el caso de la interpretación episódica, se comprende como un momento de articulación o desarticulación político-económica, por errores en la política macroeconómica doméstica o elementos exógenos, que por la conjunción de una serie de eventos y procesos ha desembocado en una crisis, facilitando diversas variables políticas y económicas en un momento dado de desaceleración de la economía brasileña o de la capacidad de articulación política del PT.

Como plantean Pedro Rossi y Guilherme Mello (2016) estas se pueden sintetizar en cuatro posiciones: a) el impacto negativo del uso de políticas heterodoxas con la adopción de la Nova Matriz Econômica (NME) en la primera administración Dilma; b) la contracción fiscal y monetaria por la adopción de políticas fiscales y monetarias restrictivas; c) problemas en la conducción macroeconómica doméstica (sobrevalorización cambial, valorización de los salarios de forma extralimitada sobre la "productividad", reducción del margen de rentabilidad de las empresas); $y$ d) fracaso de la estrategia industrialista del plan económico. A estas se suman interpretaciones sobre las condiciones exógenas macroeconómicas desfavorables, como el fin del súper ciclo de las commodities y la crisis económica mundial.

Desde esta perspectiva, pero con énfasis político, la principal razón aducida es la conjunción de dos problemas institucionales específicos: la corrupción - lo que supuestamente promovió la movilización populary la desconfianza en los sectores políticos aliados al gobierno, terminando con su base 
parlamentaria y con su capacidad de gobernabilidad (Limongi y Figueiredo, 2017; Mussi y Bianchi, 2013; Neto, 2016).

En otra vertiente, la interpretación estructural-histórica ha planteado la crisis como un momento específico en el que emergió una serie de contradicciones estructurales que ya existían en la sociedad brasileña, contradicciones del modo de producción, contradicciones institucionales que pertenecen a un proceso de democratización incompleto, contradicciones de clase, contradicciones del modelo de desarrollo, etc. La crisis es vista como consecuencia de la reproducción de la estructura contradictoria (Almeida, 2016; Bastos, 2017; Boito Jr, 2016c y 2016b; Braga, 2016a y 2016b; Carvalho, 2018; Chaui, 2016; Coggiola, 2015 y 2016; Paulani, 2017; Rossi y Mello, 2016).

Esta interpretación toma al proceso político desarrollado por el PT como un episodio que dio continuidad a las profundas contradicciones y que contribuyó a un proceso de desmovilización social, incapaz de dar una respuesta política certera a la emergencia de la crisis. Así, la crisis es vista como el producto de esa continuidad estructural y no como el fin de una tentativa o proceso político que intentó transformar las bases estructurales, económicas y políticas.

Dependiendo del enfoque que se le dé al análisis de la crisis, la exposición de variables $y$ la importancia o acento en cada una de estas, plantean escenarios diferentes. Las visiones episódicas explican la crisis desde una perspectiva técnica $y$ contextual, sin poner en tela de juicio las relaciones histórico-sociales subyacentes o sin tomarlas en cuenta, centrando su interpretación en las condiciones institucionales y mercantiles que permitieron este escenario y en las condiciones técnicas necesarias para superarlo.

La visión histórico-estructural sitúa la crisis como un momento en un proceso estructural extendido, en una coyuntura específica que muestra el agotamiento del modelo político "desmovilizador" del PT y de su política de redistribución de renta, que amplió el consumo $y$ algunos derechos sociales garantizados por el Estado, sin transformar las bases estructurales sociales y económicas.
Esta perspectiva explica la crisis por el agotamiento del modelo distributivo y su sostenibilidad en el marco de la dependencia-periférica o de una economía neoliberal, creando las condiciones para una reconstitución y profundización de la estructura neoliberal-dependiente, que en el plano ideológico reforzó la identidad monopolista de las clases burguesas nacionales (o élites) y de amplios sectores de las clases medias brasileñas identificadas con ellas.

Una tercera interpretación que merece atención es la argumentada por Leonardo Avristzer (2018), al identificar un patrón pendular en las expresiones político-históricas brasileñas, que se perciben como periodos democratizadores y periodos antidemocráticos, amparados en vías institucionales electorales y no electorales. Esto implicaría la existencia de características estructurales políticas y sociales, implicadas en la democracia brasileña que admite vías antidemocráticas accionadas periódicamente en contra de la ampliación del proceso democrático, lo que implicaría crisis políticas recurrentes como mecanismos de regresión democrática.

Cada uno de los enfoques aporta datos y análisis específicos necesarios para comprender tanto la coyuntura como las bases estructurales en las cuales la crisis se asienta y expresa. También merecen una crítica que permita analizar sus alcances y sus debilidades epistémicas, con vistas a estructurar los aportes hacia una interpretación totalizante del fenómeno.

Las interpretaciones episódicas identifican elecciones y políticas específicas, siempre y cuando se parta de la aceptación de la funcionalidad y naturalización de los marcos macroeconómicos y políticos vigentes. En este sentido, la política económica desarrollada por la primera administración Dilma puede ser un factor macroeconómico desestabilizante, y promotor en gran medida de la desaceleración económica, pero eso no explica las reacciones sociales; por ejemplo, que la mayor parte de los aliados económicos de su administración le hayan dado la espalda en el momento en que estos se beneficiaban de los subsidios económicos que el Estado les suministraba con la NME, y mucho menos la generalización de la crisis al propio contexto 
institucional (Coggiola, 2015 y 2016; Rossi y Mello, 2016; Singer, 2015a).

Apoyando este cuestionamiento, la segunda administración Dilma cambió su política económica, atendiendo los intereses del capital internacional y abandonando la NME, con un menor activismo del Estado en la política macroeconómica (Singer, 2015), lo cual profundizó la crisis y no generó respuestas positivas en la propia macroeconomía o en el contexto político.

En esta misma línea, la pérdida de la hegemonía petista no puede verse simplemente de forma contextual, debe comprenderse dentro de un sistema partidario conectado con sectores sociales específicos, que formaban su base con previa negociación y que participaban activamente en su programa de gobierno - un sector específico de la burguesía-. El quiebre fundamental de esta base no puede desligarse del impacto social que el proyecto social-desarrollista se planteaba.

La perspectiva episódica no tiene la capacidad para explicar elementos esenciales, como las mismas condiciones políticas y sociales que han permitido la semimplementación de una política económica social-desarrollista, la instauración política del proyecto petista $y$ su subsecuente crisis. Inseparable de interpretaciones técnicas, no encuentra sus raíces en las variables históricas y estructurales que les dan sentido.

La metáfora de ciclo-péndulo parece tener una base histórica brasileña, en donde se hacen ecos a los procesos políticos reformistas $y$ "modernizadores" durante el siglo xx, estructurados por procesos sociales de grandes dimensiones y la mayoría marcados por estrepitosos finales que dieron paso a gobiernos reaccionarios y autoritarios, por ejemplo, los procesos de: Getúlio Vargas, Juscelino Kubitschek, João Goulart, etc., lo cual demuestra una tendencia política interna al sistema, que conjuga una supuesta lógica de bloqueo a la democratización.

A pesar de estas bases, la interpretación pendular interpone la noción de repetición como código interpretativo de la historia, centra su interpretación en la estructura política y abandona todo análisis estructural del proyecto y prácticas políticas empleadas en los llamados procesos "pendulares"; crea por tanto, una interpretación similar a la episódica, pero exacerbando el papel político institucional de los proyectos colectivos, sin relativizar sus condiciones sociales de posibilidad, con lo cual termina renunciando a la capacidad de reacción o articulación social que da la coyuntura.

Esta interpretación termina en una paráfrasis del patrón inherente al sistema y abandona las condiciones particulares, estructurales e históricas que permiten explicar contextos, procesos y coyunturas con características radicalmente distintas a las del pasado. La interpretación estructural-histórica plantea de mejor manera o de manera más objetiva, las condiciones generales que permitieron el desarrollo de la crisis. En esta se parte desde las estructuras macrosociales hacia la configuración institucional, organizando el análisis partidario desde sus bases sociales e históricas, lo cual le da una mayor densidad $y$ alcance.

Reducir las complejidades estructurales de un país de dimensiones continentales como Brasil a elementos técnico-macroeconómicos o reducir las culturas políticas y las más diversas posiciones de clase y etnia, a una repetición histórica de "fuerzas políticas", que se refrendan en un marco definido de antemano, es reducir la crisis a los términos ideológicos que interponen salidas sintéticas a procesos sociales de alta complejidad.

El proyecto político que el PT promovía no fue un proyecto que transformó las condiciones económico-estructurales, desde la aplicación de un plan económico social-desarrollista "concretizado", este solo tomó su forma en la primera administración de Dilma y topó con frenos estructurales que lo llevaron al fracaso y a la adopción de un programa económico austero, en la línea que las herencias neoliberales de la década de los 90 había inaugurado ${ }^{3}$ (Singer, 2015).

$3 \quad$ Singer adopta el concepto de desarrollismo para nombrar las medidas adoptadas en la NME; sin embargo, existe un amplio debate que desmarca al desarrollismo en dos vertientes: el social-desarrollismo, amparado en la extensión del consumo interno como motor de desarrollo (el cual caracteriza la 
Tomar una perspectiva unidireccional de "crisis del proyecto político económico" o de "crisis del PT" como síntesis de un proyecto político masificado no es realista, la crisis tiene raíces más profundas, que deben tomar en cuenta contradicciones estructurales en las cuales el proyecto petista se inserta, como lo son el pacto democratizador de la Constitución Política de 1988, con derechos sociales constitucionalizados y el advenimiento de políticas neoliberales que contradicen estos derechos, históricamente presionando por su reforma en favor de la reducción de estos y con el incumplimiento de los marcos generales del pacto democratizador (Almeida, 2016; Bercovici, 2010; Paulani, 2016; Semer, 2016; Zaverucha, 2010).

En esta línea, si se aceptara la categoría de ciclo, esta tendría que ser entendida como ciclo de democratización, que enmarca las estructuras sociopolíticas del país en general, y no un ciclo exclusivo definido por el PT, el cual es solo un actor dentro de la estructura social, al igual que los demás partidos políticos.

No se puede entender la crisis como una crisis del PT, sino como una crisis de un proyecto social democrático que se funda en 1985, con la vuelta a la democracia y la proyección de derechos sociales $y$ civiles en una nueva institucionalidad: “... Es en esta perspectiva histórica que se comprende el período 1988-2016 como un ciclo inédito de democracia y ampliación de los espacios públicos" (Fagnani, 2017, traducción propia) ${ }^{4}$.

Tomado en este sentido, el proyecto político lulista se enmarca en un proceso político reciente que implica el cumplimiento de un pacto social liberal democrático, marcado profundamente por la constitucionalidad de derechos sociopolíticos

política petista) y el neo-desarrollismo, promovido por un sector de economistas, que se ampara principalmente en la promoción de las exportaciones de bienes manufacturados como motor dinamizador del desarrollo económico y en una política macroeconómica equilibrada, etc. Este tema será desarrollado a lo largo del texto.

4 É nesta perspectiva histórica que se compreende o período 1988-2016 como um ciclo inédito de democracia e ampliação dos espaços públicos (Fagnani, 2017). y con la necesidad de sus concretizaciones, en contraposición a procesos político-económicos marcados por la dependencia económica y la adopción del neoliberalismo como la base estructural que prometía esa concretización. Una contradicción en sus términos.

Tuvimos una Asamblea Constituyente (1986/88) en la que la correlación de las fuerzas, resultante de la movilización popular, forzaron la incorporación de diversas demandas Populares en la nueva Constitución, materializando en el Estado, que continuaba Burgués, una correlación de fuerzas (...) más contradictoria - lo que trajo después, dificultades para una gobernabilidad burguesa con base en políticas neoliberales (Almeida, 2016, p. 181, traducción propia) $)^{5}$.

Desde esta perspectiva, se señala que la crisis del periodo 2013-2019 va más allá de una crisis partidaria, un choque de campos políticos (izquierda-derecha) o las condiciones macroeconómicas implicadas en el proceso - lo cual no elimina ninguna de estas variables como participantes y decisivas en este-. Es más bien la consecuencia de las contradicciones internas de un proyecto político, estatal y democrático-liberal, desarrollado en la democratización postdictadura, articulado a una estructura político-económica dependiente-periférica que condiciona socio-históricamente las posibilidades de acción política autónoma en los diversos planos, $y$ como consecuencia presenta límites $y$ contradicciones a los procesos de transformación social pretendidos como armónicos, tal como lo fue el proceso petista.

\footnotetext{
5 Tivemos uma Assembleia Constituinte (1986/88) na qual a correlação de forças, resultante da mobilização popular, forçou a incorporação de diversas demandas populares na nova Constituição, materializando no Estado, que continuava burguês, uma correlação de forças (Poulantzas, 1977), mais contraditória - o que veio trazer, logo depois, dificuldades para uma governabilidade burguesa com base em políticas neoliberais (Almeida, 2016, p. 181).
} 
Más adelante se argumentará esta posición, pero a manera introductoria se abre el debate en algunos frentes, proponiendo las hipótesis que se defenderán:

a)

La crisis brasileña es el síntoma de un proceso de democratización incompleto, que tiene su origen y raíces en la histórica y sistemática exclusión social, económica y política de una amplia mayoría de la población; con bases en instituciones sociales y políticas nacidas de un complejo proceso de negociación de las condiciones democráticas — se refiere específicamente al periodo militar comprendido entre 1964 a 1985-. El proceso democrático vivido a partir de 1988 hasta la actualidad es una serie de experimentos políticos que procuran articular estructuras de poder a sistemas institucionales de carácter democrático, que proponen un pacto nacional hasta ahora incompleto.

b) La segunda hipótesis, separable solo analíticamente, tiene que ver con la dimensión económica y político-histórica de la crisis, con un nuevo patrón estructural de desarrollo que a partir de la década de los 80, experimenta una transformación paulatina de su composición productiva, hacia una estructura económica más dependiente de las cadenas productivas al capital internacional y a la constitución de una hegemonía política neoliberal.

Este proceso no se debe entender como un escenario de rompimiento con las dinámicas y estructuras de dependencia y subdesarrollo presentes desde el periodo industrial (años 60-70), sino como profundización de estas relaciones, estructuras y dinámicas en un escenario económico más dramático, caracterizado por fuertes procesos de desindustrialización, especialización en la producción de materias primas - commodities - y financiarización de la economía brasileña (Ayala, 2016; Belluzzo y Almeida, 2015; Diegues, 2015; Carvalho, 2018, Carvalho y Kupfer, 2011; Katz, 2016; Lavinas y Gentil, 2018; Marques y Nakatani, 2015; Martins,
2011; Mattos, 2015; Osorio, 2012; Paulani, 2003, 2009, 2016; Rossi y Mello, 2016).

Estas dos hipótesis condicionan un proyecto político contradictorio y dicotómico, el proyecto político del PT y su política económica social-desarrollista, que dan los rasgos característicos de un escenario político más contradictorio, un espacio institucional dirigido a la constitución de nuevas franjas de la población "incluidas" en el consumo masivo (Lavinas y Gentil, 2018), y la creencia de un desarrollo más autónomo, armonizado con condiciones de dependencia y políticas de austeridad (Sampaio Junior, 2012).

\section{LAS ESTRUCTURAS HISTÓRICAS DE PODER POLÍTICO Y LA DEMOCRATIZACIÓN}

Este análisis no pretende identificar las "raíces" o las variables determinantes y causales de la crisis, sino rescatar las dos dimensiones (política y económica) analizando su relación durante el proceso de despliegue de esta, identificando en el plano histórico los elementos implicados en la coyuntura. En el plano político-histórico y en un enfoque de larga duración, la democracia en Brasil es una excepción temporal, esta es la situación objetiva-institucional que enmarca la crisis $y$ a su vez es el producto de un proceso histórico de movilización popular, que se expresa en la dicotomía político-histórica entre la dictadura y la democracia, como fuentes tensionales a lo largo de la historia de las formas de gobierno.

Como plantea Jorge Zaverucha (2010), el marco institucional democrático brasileño es el producto de tensiones dialécticas internas entre la democratización política y económica, así como, el marco vivo determinante de la dictadura y sus instituciones autoritarias, que operan actualmente como dispositivos, dentro del propio orden democrático - uno de estos es el poder judicial-. Este es un rasgo característico y limítrofe. Esto conduce a identificar a la democracia liberal actual y a su marco constitucional como el producto de tensiones históricas internas que se enmarcan en relaciones de dominación y explotación, determinantes de los alcances concretizados por 
el aparato jurídico y social, conquistado en el proceso constituyente de 1988.

Sin identificar cualquier causalidad exclusiva, esta situación brinda un marco político general que permite pensar la estructura económica y el marco dialéctico tensionado que definen los limites contextuales de la tensión política expresa en el proceso de democratización que formula hoy la situación de crisis.

Para Brasil, el énfasis político-analítico debe llevar a analizar la configuración particular de tensiones en torno al proyecto democrático y no a un supuesto "cambio social radical" promovido por los gobiernos petistas. El proyecto en crisis es la democracia liberal $y$ lo que se expresa es un proceso de desdemocratización, que define límites de participación política-ciudadana y económica, en favor de las condiciones generales de su reproducción social ampliada. Preguntarse qué tanto la determinación de la crisis es económica o política es un error epistémico-histórico en el énfasis, que no permite comprender las relaciones dialécticas internas al proceso, tanto en su estructura económica como político institucional.

La democracia institucionalizada brasileña entra en juego con promesas y se encuentra con límites objetivos, determinados por las propias relaciones sociales de dónde emerge $y$ dónde se desarrolla. Las tensiones que emergen de esta contradicción son la expresión de dos modelos estructurales incapaces de reproducirse a largo plazo. Tanto la democracia como la estructura económica es incapaz de profundizarse, una en detrimento de la otra, no existe armonía dimensional y estas expresan las contradicciones inherentes a las relaciones de explotación en la sociedad.

En este caso, se cumple lo retomado por Alain Touraine (2000) en su paráfrasis de Georges Burdeau "La democracia política...es sucedida por la democracia social y el triunfo del pueblo real. Lo que entraña necesariamente una ruptura revolucionaria..." (Touraine, 2000, p. 171). En el caso brasileño, el pasaje sería bloqueado por su estructura y expresado por su carácter elitista y conservador, como diría y defendería la propia cúpula militar del golpe de 1964, su bloqueo se daría por "revoluciones preventivas", que de "revoluciones" se puede transcribir a "golpes preventivos" de la democracia (Avritzer, 2018; Ribeiro, 2015).

Estos son límites del proyecto políticohistórico, el patrón encontrado por las nociones interpretativas de la crisis como "ciclos" o "péndulos" son en realidad continuidades estructurales de la "reproducción social ampliada" de la explotación, que dan carácter a la estructura político-económica, tal como lo describió Darcy Ribeiro (2015):

En esas condiciones, se exacerba el distanciamiento social entre las clases dominantes $y$ las subordinadas, $y$ entre éstas y las oprimidas, agravando las oposiciones para acumular, bajo la uniformidad étnico-cultural y de la unidad nacional, tensiones disociativas de carácter traumático. En consecuencia, las elites dirigentes, primero lusitanas, después luso-brasileñas y, al final, brasileñas, vivieron $y$ viven aún bajo el pavor pánico del alzamiento de las clases oprimidas. Una buena expresión de este pavor pánico es la brutalidad represiva contra cualquier insurgencia y la predisposición autoritaria del poder central, que no admite ninguna modificación del orden vigente (p. 20, traducción y cursivas propias) ${ }^{6}$.

Pero no existió ninguna "insurgencia" en el contexto actual, sino el proceso señalado por Touraine, alcanzado simbólicamente en el proceso de democratización que, en el devenir de la

$\overline{6}$ Nessas condições, exacerba-se o distanciamento social entre as classes dominantes e as subordinadas, e entre estas e as oprimidas, agravando as oposições para acumular, debaixo da uniformidade étnico-cultural e da unidade nacional, tensões dissociativas de caráter traumático. Em consequência, as elites dirigentes, primeiro lusitanas, depois luso-brasileiras e, afinal, brasileiras, viveram e vivem ainda sob o pavor pânico do alçamento das classes oprimidas. Boa expressão desse pavor pânico é a brutalidade repressiva contra qualquer insurgência e a predisposição autoritária do poder central, que não admite qualquer alteração da ordem vigente (Ribeiro, 2015, p. 20). 
"democracia liberal", pretende completar simbólica y jurídicamente la "democracia social" como necesidad para la reconfiguración de una estructura social más armónica y participativa, siempre dentro de los límites de la estructura heredada y sin llegar a un supuesto rompimiento "revolucionario".

Es este marco contradictorio, complejo $y$ tensionado, el que da contexto a los procesos del pacto social democratizador, caracterizado por: un marcado conflicto en su concretización, una estructura que bloquea e incumple tal pacto y una tendencia a la represión de la "democracia social", delimitada por estructuras económicas dependientes del mercado global que, implican poca participación social y una drástica reducción de los derechos simbólicamente conquistados.

El "lulismo" es un programa contornado por estas contradicciones inherentes $y$ es también la proposición de una fórmula "progresiva y armónica" que intentó romper la lógica polarizadora inherente a las condiciones de posibilidad democrática, facilitando la progresión de la "democracia social" sin quebrantar la estructura económica y política que limitaba su avance, en cierta medida la idea es de una valentía admirable, pero su resultado es el producto mismo de la lógica anticipada.

En este sentido, es que las vías de concretización escogidas por el "petismo" fueron las tildadas como "asistencialistas", las vías presupuestadas en la exclusiva capacidad institucional que concretizó la inclusión social al consumo y a la educación, con acciones afirmativas en las universidades, transferencia de renta a las familias en extrema pobreza, el aumento sostenido del salario, el acceso a bienes de consumo tecnológicos y al crédito, en un contexto económico de crecimiento sostenido (Singer, 2009 y 2015). Pero el núcleo estructurante de la sociedad fundada en el proceso democratizador incompleto continuaba atado a sus contradicciones políticas, institucionales y económicas, no resueltas en los términos estatales y mucho menos en la reconfiguración de la estructura desigual y excluyente heredada, tensionando estrategias para concretizar promesas democráticas pactadas.
En este sentido, algunos autores son más pesimistas en su visión de esta situación, identificando las propias continuidades de la dictadura militar brasileña en el marco legal y la función política asumida por el pacto constitucional de 1988, en donde las estructuras de "poder" militar son sostenidas por dispositivos de control político y social de carácter autoritario $^{7}$, como el propio protagonismo militar y su función de orden ${ }^{8}$ o la propia estructura administrativa: "La cuestión del control democrático de la intervención económica y social del Estado continúa sin solución bajo la democrática Constitución de 1988 y toda su estructura administrativa, aún heredada de la dictadura militar" (Bercovici, 2010, p. 90, traducción propia) ${ }^{9}$.

El contexto institucional es caracterizado por un proceso de democratización incompleto $y$ vacilante, que no terminó de nacer cuando ya estaba siendo deteriorado por las propias estructuras de poder que se imponen $y$ conducen su nacimiento. Esta es la característica política principal, la paradoja particular que da sentido a la crisis del periodo 2013-2019 y que contorna la emergencia y configuración de una dinámica ideológica "antidemocrática" y el desarrollo de un proceso de "desdemocratización" acelerada.

La estructura básica sobre la cual se constituyó la promesa democratizadora "liberal" y "social" se demuestra como la determinante de sus alcances y límites. Sobre ella los contornos de la "reproducción social ampliada" del sistema y la emergencia de limites más amplios y marcados para el proyecto democrático,

$7 \quad$ Estas tesis son defendidas $y$ estudiadas en Teles $y$ Safatle, 2010.

8 La Constitución Brasileña preserva en su art. 142, la función de las Fuerzas Armadas de "garantía de los poderes constitucionales, $y$ por cualquiera de estos, de la ley y el orden" (Constituição da República Federativa do Brasil, 2017).

9 A questão do controle democrático da intervenção econômica e social do Estado continua sem solução sob a democrática Constituição de 1988 em toda sus estrutura administrativa, ainda herdada da ditadura militar (Bercovici, 2010, p. 90). 
en favor de la extensión de la estructura material que la alimenta.

\section{LA ECONOMÍA-POLÍTICA DEL "SOCIAL- DESARROLLISMO”: LÍMITES Y CRISIS}

Las características particulares del contexto político antes analizadas, enmarcan el dilema y la contradicción estructurante puntualizada hace algún tiempo por Samir Amin (1974): "Dentro del modo capitalista, la democracia es la resultante de dos exigencias internas del sistema: por una parte, la competencia entre capitalistas privados y por otra la dominancia de la instancia económica y el carácter economista de la ideología” (p. 393).

Es en este contexto dimensional que los proyectos democráticos $-y$ económicos- tienen su sentido, con todas las heterogeneidades, particularidades y complejidades del contexto específico. Los límites del proyecto lulista, la forma ideológica y las condiciones preparatorias de la "crisis" son las condiciones determinadas por la necesidad expansiva de la "reproducción social ampliada" del capitalismo brasileño y sus particularidades, cabe afirmar, no intervenidas por el proyecto "social-desarrollista".

En términos generales, la política "petista" se caracterizó por apuntalar o intentar desenvolver un nuevo proyecto "desarrollista", lo que implicaba una profunda reflexión y reconfiguración del llamado "viejo desarrollismo", caracterizado por una política de sustitución de importaciones, políticas comerciales restrictivas y una industrialización "acelerada".

Para el "petismo" y para varios economistas heterodoxos, esta forma implicaba límites, incapacidades $y$ nuevos escenarios, entre ellos, un nuevo contexto caracterizado por una mayor apertura de mercado y dinámicas globales. En esta línea, dos grandes perspectivas se situaron dentro de las administraciones del PT, en torno a la constitución de proyectos alternos al "Neoliberalismo" y al propio "Desarrollismo". La primera, hegemónica y adoptada parcialmente $^{10}$ por la administración Dilma Rousseff

10 André Singer (2015) llama a esta política de forma genérica como "desarrollismo", pero confluye en llamada "Social-desarrollismo"11 y la segunda llamada "Neo-desarrollisma"12 promovida desde sectores gubernamentales, think tanks y parte del bloque de apoyo al "petismo" (Bastos, 2012).

Al respecto, la literatura económica caracteriza al "Social-desarrollismo" en términos generales, sin que exista una definición estructurada como sí existe con el "Neo-desarrollismo". Este propone una política económica orientada por el Estado en dirección a una mayor distribución de renta desde el sector público, promoviendo la ampliación del mercado interno centrado en el consumo doméstico (Bastos, 2012).

A diferencia de este, el "Neo-desarrollismo" se ha planteado de forma más estructurada, principalmente por economistas de renombre como Luiz Carlos Bresser-Pereira (2012 y 2016), João Sicsú, Luiz Fernando de Paula y Renaut Michel (2007), José Luis Oreiro, Nelson Marconi, entre otros (Marconi y Oreiro, 2016; Oreiro, 2012; Marconi y Brancer, 2017). En este se plantea un cambio estructural en favor de la industrialización y con énfasis en exportaciones de bienes manufacturados tecnológicos, esta perspectiva defiende una mayor estabilidad macroeconómica operada por la elevación de la productividad, control del tipo de cambio $y$ un mayor equilibrio fiscal por parte del Estado, en donde el sector privado constituye el centro económico.

Como sintéticamente plantea Pedro Bastos (2012), el "Social-desarrollismo" se caracterizaría por un énfasis distributivo orientado por el Estado, mientras que el "Neo-desarrollismo" por exportaciones manufacturadas del sector privado. De las dos matrices, la adoptada hegemónicamente por el PT ha sido la "social-desarrollista", articulando - como se verá más adelante- el crecimiento del mercado interno con énfasis en el consumo doméstico y la valorización del salario, la expansión del gasto público y estrategias de inversión dirigidas por el Estado y sus empresas

su análisis y remarca el carácter parcial y fugaz de su aplicación política con la NME.

11 Social-desenvolvimentismo.

12 Novo-desenvolvimentismo. 
estatales. Los "Neo-desarrollistas" atribuyen la crisis económica a esta línea.

Sean sus interpretaciones de orientación heterodoxa u ortodoxa, el punto común referido por los economistas como determinante de la "crisis" es la adopción de la política económica petista ${ }^{13}$. Para los ortodoxos, esta significó una supuesta política "intervencionista" que apoyó su desarrollo en el crecimiento del gasto público y en la intervención en ciertos sectores del mercado; para heterodoxos significó lo contrario, el abandono de la política económica sostenida hasta 2015, la adopción de una política recesiva y la incapacidad para concretizar cambios estructurales (Rossi y Mello, 2016).

Sin embargo, la hipótesis de esta investigación varía en su sentido teórico, pues esas condiciones e indicadores solo señalan la necesidad de una reacción económica, pero no su necesario sentido, este dependió de la lógica interna y del modelo a "reproducir" dentro de los límites y estructuras determinadas en las condiciones económico-políticas brasileñas.

Antes de continuar en esta línea, se plantean algunas preguntas que guían el análisis político-económico ¿Es posible sostener un proceso político de reforma, respetando y armonizando las estructuras político-económicas del neoliberalismo $y$ las particularidades estructurales de una situación periférico-dependiente?, ¿es posible profundizar las democracias y por ende, la participación democrática en estos términos? y aún más radical, ¿es posible reformar las relaciones sociales e históricas de dominación, armonizando y respetando las estructuras económicas que la sostienen, en un supuesto proceso progresivo?

Para los economistas Pedro Rossi y Guilherme Mello (2017) del Centro de Estudos de Conjuntura e Política Econômica de la UNICAMP, la "crisis" encuentra su razón de ser en un proceso muy claro, un "choque recesivo" que se promueve progresivamente desde el $1^{\circ}$ semestre de 2015, con la aplicación de una abrupta política de austeridad que intervino con: un "choque fiscal" contrayendo la demanda pública, un "choque en los precios administrados" que promovió una menor presión de costos a las empresas pero una mayor presión al consumo familiar, un "choque cambial" que promovió una desvalorización del $\mathrm{R} \$ / \$$ en $50 \%$ de su valor y un "choque monetario" con el aumento de las tasas de interés, afectando las piedras angulares de la política económica y social petista.

13 Un claro recuento y análisis de los puntos de vista puede encontrarse en Rossi y Mello (2016). 


\section{GRÁFICO 1 \\ TASA DE CRECIMIENTO ANUAL DEL PIB Y PIB PER CÁPITA DE BRASIL 2002-2016}

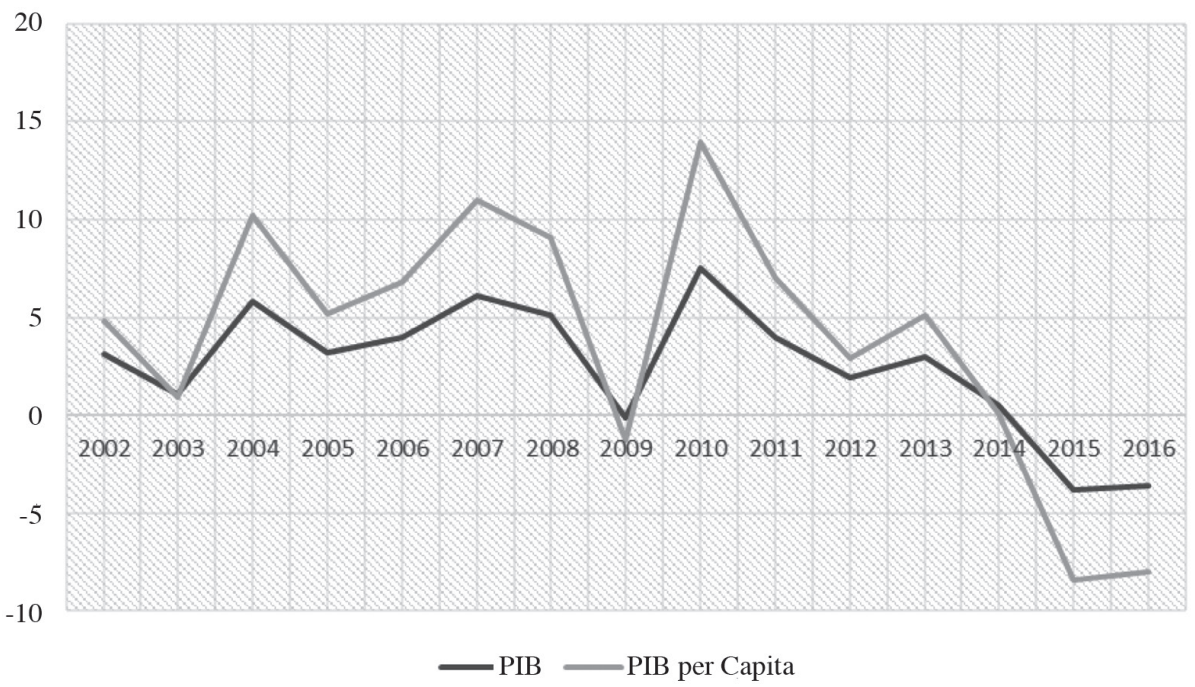

Fuente: Instituto Brasileño de Geografía Estadística (IBGE), 2017.

En términos sintéticos, la profundización de la "crisis" y su estabilización como recesión a partir de la desaceleración económica - la mayor crisis de la historia brasileña, según los autores $^{14}$ — pueden ser explicadas por la adopción de una política económica dirigida a la "austeridad de choque", una salida adoptada por la segunda administración Dilma Rousseff y dirigida a la "destrucción" del propio motor político y económico de los gobiernos "petistas": el "consumo" y el "empleo".

En el año 2015, ante la fragilidad de la economía brasileña, el gobierno optó por un choque recesivo o en otras palabras, echo mano a un conjunto

$14 \quad$ En un análisis comparativo de las contracciones del PIB experimentadas en las crisis brasileñas de 1929, 1980, 1989 y 2014, los autores identifican la crisis del periodo 2013-2019 como la mayor contracción histórica del PIB y por tanto, la crisis más profunda experimentada por la economía brasileña. El Gráfico 1 ejemplifica la caída del PIB en -4 puntos porcentuales para 2015, año del impeachment. de políticas de austeridad económica. De acuerdo con el diagnóstico entonces dominante, el objetivo de ese "ajuste" era enfrentar, de una sola vez, los "desequilibrios" de la economía brasileña que se referían tanto a las cuentas públicas como a los precios administrados. Además, para algunos analistas, el mercado de trabajo sobrecalentado también era una fuente de desequilibrio cuyo remedio era el aumento del desempleo y la reducción de salarios reales (Rossi y Mello, 2017, p. 3, traducción y cursivas propias $)^{15}$.

15 Em 2015, diante da fragilidade da economia brasileira, o governo optou por um choque recessivo ou, em outras palavras, lançou mão de um conjunto de políticas de austeridade econômica.

De acordo com o diagnóstico então dominante, o objetivo desse "ajuste" era enfrentar, de uma só vez, os "desequilíbrios" da economia brasileira que diziam respeito tanto às contas públicas quanto à preços administrados. Além disso, para alguns analistas, o mercado de trabalho sobreaquecido 
Este argumento es validado por algunos economistas heterodoxos (Bastos, 2017; Carvalho, 2018), aunado a factores exógenos al ciclo económico, como la política económica estadounidense o la caída del precio de las materias primas (commodities), siendo estos facilitadores de la desaceleración previa. Lo que permite comprender cómo la propia estructura económica brasileña refleja la vulnerabilidad y la sostenibilidad de una política económica "social-desarrollista".

Para Franklin Serrano y Ricardo Summa (2018) este choque es una reacción a un "conflicto distributivo" generado por una tendencia al crecimiento de los salarios reales, amparada en la política de empleo/consumo y en el creciente poder de negociación de los trabajadores, que paralelamente se expresó en un relativo estancamiento de la tasa de crecimiento. Según los autores, es en este contexto, marcado por una presión indirecta de la clase capitalista, que el gobierno petista reacciona, formulando una resolución en favor de la tasa de crecimiento y de la clase capitalista por medio de una política-económica de austeridad.

Lo señalado demuestra una reacción económica que responde a los limites demarcados al proyecto "social-desarrollista", el cual implicaba una política de inclusión social, la ampliación del mercado interno de consumo, la socialización de la renta y raquíticamente un proceso de industrialización, amparado en las tendencias del patrón neoliberal de inserción al mercado internacional y la configuración de procesos de financiarización y destrucción de los circuitos productivos de valor agregado ${ }^{16}$ (Carvalho, 2018; Carvalho y Kupfer, 2011; Marques y Nakatani, 2015).

Como caracterizaba Plínio de Arruda Sampaio Jr (2012), esta política económica pretende ser armónica, defendiendo estrategias de

também era uma fonte de desequilíbrio cujo remédio era o aumento do desemprego e redução de salários reais (Rossi y Mello, 2017, p. 3).

Para economistas "Neo-desarrollistas" como Nelson Marconi y José Luis Oreiro (2016), la regresión productiva es una tendencia presente desde 2005 , no intervenida ni profundizada por la política macroeconómica. convivencia equilibrista que pretenden fomentar el crecimiento económico y otras que facilitan la movilidad social.

Por encima de sus diferencias e idiosincrasias de orden teórico y práctico, los economistas que reivindican el nuevo desarrollismo comparten un denominador común: buscan una tercera vía que evite lo que consideran el grave problema del neoliberalismo - la complicidad con el rentismo-y lo que atribuyen como las inaceptables perversidades del viejo desarrollismo - el nacionalismo anacrónico, la complacencia con la inflación y el populismo fiscal (...) (Sampaio Junior, 2012, p. 679, traducción propia) ${ }^{17}$.

Como se verá, la crisis es el producto de un guion trazado que pretendía cambios estructurales progresivos, en tanto, las variables supuestas como "independientes" fueran sostenidas: estabilidad de la moneda, competitividad internacional $y$ austeridad fiscal. Es precisamente la base "exitosa" del modelo la que se sacrifica, la cual se encuentra compuesta por variables "dependientes" como el empleo y el consumo doméstico, así como, las políticas económicas "diferenciadas".

Como identificaron Lena Lavinas y Denise L. Gentil (2018), la política social "petista"

$17 \quad$ Acima de suas diferenças e idiossincrasias de ordem teórica e prática, os economistas que reivindicam o novo desenvolvimentismo compartilham um denominador comum: procuram uma terceira via que evite o que consideram o grave problema do neoliberalismo - a cumplicidade com o rentismo- e o que atribuem como as inaceitáveis perversidades do velho desenvolvimentismo —o nacionalismo anacrônico, a complacência com a inflação e o populismo fiscal. 0 desafio do neodesenvolvimentismo consiste, portanto, em conciliar os aspectos "positivos" do neoliberalismocompromisso incondicional com a estabilidade da moeda, austeridade fiscal, busca de competitividade internacional, ausência de qualquer tipo de discriminação contra o capital internacional - com os aspectos "positivos" do velho desenvolvimentismo - comprometimento com o crescimento econômico, industrialização, papel regulador do Estado, sensibilidade social (Sampaio Junior, out./ dez, 2012, p. 679). 
era caracterizada en su estructura económica por una dependencia y sumisión a las dinámicas de financiarización, estas se alimentaban en parte de la articulación de sectores estratégicos como servicios de salud, educación superior $y$ seguridad social a agentes financieros $y$ sectores privados, promoviendo el crecimiento del "gasto privado" en estos sectores. Para las investigadoras esta situación devela la fragilidad estructural e institucional implícita en la propuesta "petista".

¿Cómo explicar que, a la sombra de un contrato social innovador, ratificado en la Constitución de 1988 y a lo largo de un ciclo de crecimiento bajo la norma del Estado democrático de derecho, liderado por un partido de centroizquierda, los avances registrados han sido modestos $y$, además, susceptibles de reversión casi integral, como indican las reformas aprobadas en el post-impeachment (...) que echa por tierra derechos sociales $y$ la expectativa de construcción de una sociedad más igualitaria? Cómo justificar que la política social no se haya utilizado para fortalecer el sistema de seguridad, sino que, por el contrario, ha contribuido a debilitarlo, a través del desbordamiento de la provisión pública, en virtud de la sub-financiación (Lavinas y Gentil, 2018, p. 194, traducción propia $)^{18}$.

La respuesta y las razones yacen en los propios límites estructurales, y más que en

18 Como explicar que, à sombra de um contrato social inovador, ratificado na Constituição de 1988, e ao longo de um ciclo de crescimento sob a regra do Estado democrático de direito, liderado por um partido de centroesquerda, os avanços registrados tenham sido modestos e, ademais, passíveis de reversão quase integral, como indicam as reformas aprovadas no pósimpeachment... que jogam por terra direitos sociais e a expectativa de construção de uma sociedade mais igualitária? Como justificar que a política social não tenha sido usada para fortalecer o sistema de seguridade, mas, ao contrário, tenha contribuída para debilitálo, através do sucateamento da provisão pública, por força do subfinanciamento (Lavinas y Gentil, 2018, p. 194). ellos, en la lógica interna de la "reproducción social ampliada" de la estructura particular del capitalismo brasileño, el "ornitorrinco" como lo bautizó genialmente el sociólogo Francisco (Chico) de Oliveira (2003), que presenta disparidades estructurales radicales, implicando relaciones contradictorias entre sectores altamente desarrollados y sectores extremadamente pobres, incapaz de articularse y con tendencias a la degradación económica y social.

Aunque la situación descrita por Oliveira obedece a una caracterización general del periodo "prelulista", esta vislumbra las tendencias, formas estructurales y límites a los cuales el proyecto "armónico" se planteaba respetar, en tanto, transformara solo algunas de sus tendencias como el empleo, el consumo o el crédito, sin alcanzar al final de cuentas, la reconfiguración de las tendencias degradantes y contradictorias.

De hecho, autores especializados en los periodos "lulista-petista" en general, como André Singer (2015), han planteado que la experiencia económica "social-desarrollista" se delimita a un fugaz experimento de mero control de la política económica en 2014, en favor de una supuesta reconfiguración del sector "industrial" como nuevo actor económico, más allá del "sector primario" y "secundario"; el control de los mecanismos de la política monetaria en favor de un desarrollo más endógeno, como la reducción de las tasas de interés - de las más altas del mundo-; control sobre el flujo de capitales; desvalorización del real; exoneraciones a sectores estratégicos; aranceles aduaneros favorables a la producción nacional, etc.

Esta política se concretó en la aplicación de la Nova Matriz Econômica (NME) implementada durante la segunda mitad del gobierno Dilma Rousseff (2013-2014) y que se vio truncada por la presión de los sectores financieros y la respuesta adversa de los propios sectores "industriales" que recibían sus beneficios; los cuales estaban divididos por las supuestas visiones "social-desarrollistas", pero unificados en contra de la experiencia implicada por la supuesta transformación de la estructura capitalista dependiente. Esta unificación es uno de los enigmas colocados en torno a la discusión 
sobre el fracaso de la NME, la salida "austera" adoptada después y el impeachment a Dilma Rousseff.

Es en este contexto que la crisis se configura en un escenario cada vez más complejo, principalmente en la dimensión política, desembocando en la acción de las tendencias, variables y dispositivos "independientes" que el proyecto "social-desarrollista" defendía como eje central de su política económica, de aquí en adelante la "crisis" es "provocada" en favor de la "reproducción ampliada del capital", es decir, la búsqueda y la reconfiguración de nuevos capitales por explotar.

A partir de ahí, el desarrollismo ofrece resistencia sorda, pero crecientemente debilitada, a la presión en favor del choque neoliberal. En los meses siguientes, además del aumento continuo de los intereses, el recorte en la inversión pública, el aumento de la tasa de retorno en las concesiones, la disminución de las restricciones al capital especulativo y las privatizaciones en el área de transportes irían punteando la vuelta atrás (Singer, 2015, p. 54, traducción propia) ${ }^{19}$.

En cuanto a la enigmática "confabulación" de los sectores, o para ser más precisos de la burguesía ligada al capital nacional y la ligada al capital especulativo-rentista-financiero, quizá se debería plantear una hipótesis sustentada en su "relación" y no en una supuesta contraposición de "clase". Como recuerdan Franklin Serrano y Ricardo Summa (2018) en su paráfrasis Kaleckiana: "los capitalistas no invierten como clase" (p.181), se puede agregar que funcionan de forma unificada en favor de la lógica interna de su reproducción, no solo en el

19 A partir daí, o desenvolvimentismo oferece resistência surda, porém crescentemente enfraquecida, à pressão em favor do choque neoliberal. Nos meses seguintes, além do aumento contínuo dos juros, o corte no investimento público, o aumento da taxa de retorno nas concessões, a diminuição das restrições ao capital especulativo e as privatizações na área de transportes iriam pontilhando a volta atrás (Singer, 2015, p. 54). plano económico sino en el propio plano político, cultural, ideológico y social.

Por tanto, su reacción no obedece solo a las tendencias económicas, sino a las políticas también, la reacción unificadora de la burguesía se sustenta en las "relaciones sociales" y no en dimensiones separadas, como fue planteado en la primera $y$ segunda parte. En el periodo lulista se aparentaba la tendencia armónica a la concretización de los derechos sociales $y$ de la democracia en el plano de un proyecto contradictorio, donde al final la supuesta "armonía" no conseguía sostener una estructura económico-social e histórica "contradictoria" sin transformar varios de sus elementos.

En este caso, los dos sectores de la burguesía deben verse como "intereses relacionales", "ligados", equilibrados en torno a las condiciones generales de "reproducción social ampliada" y de la dinámica de "acumulación", por eso están sujetos a una relación estructural y coordinados en competencia, esta relación permite pensarlos estructuralmente unidos, como "clase social", "el propio mecanismo del proceso de producción capitalista se encarga de vencer los obstáculos pasajeros que él mismo crea" (Marx, 1972, p. 523).

Como argumenta Armando Boito Jr (2016b), esto no impide identificar "conflictos" entre sectores de la burguesía, de hecho, la emergencia de los proyectos "desarrollistas", su capacidad de articulación y el apoyo que estos sostenían, tienen sentido por el soporte de un sector de la burguesía interna, que logra constituir una cierta hegemonía político-económica, aprovechando la "crisis internacional", en detrimento del otro sector más dependiente e integrado al capitalismo internacional, de línea neoliberal y que había perdido la hegemonía en el contexto "petista". Dadas las condiciones frágiles inherentes al proyecto $y$ a la preservación de las bases de la inserción neoliberal al mercado internacional, a partir de la desaceleración, el sector "rentista" emprende la reconstrucción de la hegemonía política y condiciona el proyecto "desarrollista" dependiente.

A principios de 2013, el capital internacional y la fracción de la burguesía a él integrada, iniciaron una ofensiva política 
contra el gobierno de Dilma. Debemos denominarla una ofensiva restauradora, porque su objetivo era restaurar la hegemonía del neoliberalismo puro y duro. Esas fuerzas vieron en la declinación del crecimiento económico la oportunidad de luchar contra las medidas de radicalización del neo-desarrollismo tomadas por la presidenta Dilma (Boito Jr, 2016b, p. 28 , traducción propia) ${ }^{20}$.

Es necesario subrayar que este proceso siempre fue dependiente de la propia inserción brasileña al mercado mundial, marcada internamente por políticas profundizadoras de la inserción dependiente-periférica, sin un desarrollo endógeno $y$, como ya fue planteado, sobre las bases de las propias estructuras económicas creadas por los sectores integrados al capital internacional, los llamados sectores "cosmopolitas"21.

En este sentido, no hay un sustrato nacionalista-económico en el proceso, un salto hacia la autonomización de los circuitos de capital y la competencia en el escenario internacional, lo que existe es el aprovechamiento de una coyuntura político-económica y una pugna competitiva, incapaz de romper - por sus propias características - con el capital internacional, al cual los sectores de la burguesía interna están "también integrados".

A esto obedece la "unificación", no a la constitución de posiciones políticas supuestas como internas/externas, sino a la competencia inscrita en la propia estructura, sin romper con

$20 \quad$ No início de 2013, o capital internacional e a fração da burguesia a ele integrada iniciaram uma ofensiva política contra o governo Dilma. Devemos denominá-la uma ofensiva restauradora, porque seu objetivo era restaurar a hegemonia do neoliberalismo puro e duro. Essas forças viram no declínio do crescimento econômico a oportunidade de lutar contra as medias de radicalização do neodesenvolvimentismo tomadas pela presidenta Dilma (Boito Jr, 2016b, p. 28).

21 La expresión proviene de Claudio Katz (2016) al referirse a los sectores neoliberales como sectores que promueven un proyecto sociocultural cosmopolita, más amplio que lo exclusivamente económico. esta o redefinirla. Por eso, la alineación obedece a la hegemonía y control del capital internacional, capaz de intervenir la estructura en un espacio dependiente periférico, con todas las características particulares que esto significa y sus diferencias con los centros de acumulación de capital, es decir, no hay "unificación", hay reconstitución del patrón hegemónico.

Por este sentido "relacional hegemónico" - característico de una formación social periférica $y$ en particular por la integración del capitalismo brasileño- es que la reacción capitalista adquiere un sentido estructural, como proceso de "profundización" que desencadena la "crisis" en sus diversas facetas. La "crisis" es el producto de las propias contradicciones internas al sistema.

Como bien ha planteado Leda Maria Paulani (2017), el sistema capitalista brasileño como tal, debe ser pensado como un sistema integrado, determinado profundamente por el proceso de financiarización, perentorio en las decisiones empresariales e integrante de los capitales internos, marcado por una presencia estructurante del capital internacional en las propias empresas "estatales".

Todo el marco institucional que enmarca hoy el funcionamiento del capitalismo brasileño fue construido a partir del principio mayor de atender con rapidez $y$ precisión los intereses de la riqueza financiera, en particular de los acreedores e inversores externos. Este rasgo permanece prácticamente intacto a lo largo de los gobiernos de FHC y de Lula/Dilma, a pesar de las diferencias que los separan. Es de esta forma que se explican la enorme apertura financiera, con ausencia de cualquier control sobre los flujos internacionales de capital, la internacionalización del mercado brasileño de bonos, las concesiones tributarias a propietarios de acciones $y$ las ganancias financieras de no residentes, los cambios legales para dar mayor garantía a los acreedores del Estado (Ley de la Responsabilidad Fiscal) $y$ del sector privado (reforma de la Ley de quiebras), las alteraciones en el régimen 
general de la seguridad social (INSs) y en los regímenes propios de servidores públicos y, last but not least la adopción de un recetario macroeconómico agresivamente orientado hacia el beneficio de la riqueza financiera, basado en la austeridad fiscal $y$ en tasas reales de intereses absurdamente elevadas, a menudo las campeonas del mundo (Paulani, 2017, p. 30, traducción propia, cursivas del original $)^{22}$.

Este rasgo no impide la competición y el conflicto, ni determina permanentemente el carácter del capitalismo brasileño, pero sí determinó en gran medida la resolución del conflicto y el carácter hegemónico del sistema capitalista.

La financiarización es también un mecanismo de conexión y control internacional, que opera por medio de la deuda externa e interna, influenciando, mediando $y$ determinando: los mecanismos implicados en la estructuración de la política económica, la orientación productiva de la inversión de capital y la propia composición "orgánica del capital", alineando estos procesos a las dinámicas de "acumulación de

22 Todo o arcabouço institucional que emoldura hoje o funcionamento do capitalismo brasileiro foi construído a partir do princípio maior de atender com presteza e precisão os interesses da riqueza financeira, em particular dos credores e investidores externos. Esse traço permanece praticamente intocado ao longo dos governos de FHC e de Lula/ Dilma, a despeito das diferenças que os separam. É dessa forma que se explicam a enorme abertura financeira, com ausência de qualquer controle sobre os fluxos internacionais de capital, a internacionalização do mercado brasileiro de bônus, as concessões tributárias a proprietários de ações e a ganhos financeiros de não residentes, as alterações legais para dar maior garantia aos credores do Estado (Lei da Responsabilidade Fiscal) e do setor privado (reforma da Lei de Falências), as alterações no regime geral previdenciário (INSS) e nos regimes próprios de servidores públicos e, last but not least, a adoção de um receituário macroeconômico agressivamente voltado para o benefício da riqueza financeira, baseado na austeridade fiscal e em taxas reais de juros absurdamente elevadas, frequentemente as campeãs do mundo (Paulani, 2017, p. 30). capital global" y "reproducción social ampliada" del sistema (Lapavitsas, 2016; Paulani, 2009).

La deuda es una expresión de este fenómeno, complejo y expreso dentro de la propia capitalización de empresas estatales y privadas, cada vez más determinadas por las propias inversiones de capital internacional, operando en el plano estatal como privatización directa o indirecta (Lavinas y Gentil, 2018). Como planteó la economista Rosa Maria Marques y Pablo Nakatani (2015), esta es la mayor fragilidad de la economía brasileña, en gran medida fue la base del proyecto "social-desarrollista", que reaccionó según el guion económico trazado por esta dinámica.

\section{CONCLUSIONES}

El experimento "social-desarrollista", fugaz e incapaz de articular una política económica capacitada para sostener sus elementos exitosos de movilidad social, se develó en el transcurso de la desaceleración económica como la articuladora de la profundización de las contradicciones inherentes al sistema, promoviendo y facilitando una política socialmente regresiva, en favor de su supuesta estructura "equilibrada y armónica". La "crisis" no es el producto puro del "social-desarrollismo", sino de las contradicciones estructurantes del capitalismo brasileño, que evidenció el fortalecimiento de estas contradicciones $y$ la incapacidad de articulación económica y política de una respuesta alternativa, deviniendo en un marcado proceso de desdemocratización.

La base estructural determinó la superficie política, el colapso del sistema implicó una caída acumulada del PIB superior al 7\%, un crecimiento acelerado del desempleo que solo para el $1^{\circ}$ semestre de 2017 había alcanzado el 12,6\% (50\% más que la tasa de 2014, la cual era de $6,4 \%{ }^{23}$ ) y la decreciente capacidad del consumo doméstico. En resumen, la caída de los pilares del proyecto político "petista-desarrollista".

Como se desarrolló en el artículo, esta expresión obedeció a procesos políticos

23 Instituto Brasileiro de Geografia y Estadística (IBGE): http://saladeimprensa.ibge.gov.br/noticias?v iew $=$ noticia\&id $=1 \&$ busca $=1 \&$ idnoticia $=3380$ 
$y$ económicos diversos, interrelacionados $y$ dependientes entre sí. El primero caracterizado por la configuración de un proceso de democratización incompleto que devino en un proceso de reconfiguración democrática para tendencias internas de reducción y limitación del propio proceso inaugurado, un proceso de desdemocratización.

En este proceso, la promesa del pacto democrático-social inaugurada en 1988, se caracterizó por la preservación de estructuras internas heredadas del Estado establecido por la dictadura y la limitación económico-social para la concretización de los derechos sociales establecidos en el pacto democrático.

Esto obedeció en gran medida al desarrollo de una estructura económica contradictoria con la promesa social, que se articuló a partir de reformas parciales neoliberales, una profundización de la dependencia político-económica en el contexto de la globalización y la profundización de tendencias de financiarización de la economía, creciente desindustrialización y primarización, etc. Esto implicó limites económicos para la concretización del pacto democrático-social.

En este contexto, se ha caracterizado el proceso petista como un proyecto "armónico" que tenia como objetivo la configuración de equilibrios sociales, políticos y económicos entre estas dos tendencias contradictorias, configurando como salida hegemónica la aplicación de un programa "social-desarrollista", aplicado fugazmente e incapaz de articular una respuesta a una profundización de las tendencias implicadas, la configuración de un escenario de "crisis" y la reconstitución del "neoliberalismo" como programa político-económico hegemónico.

En términos sintéticos, la "crisis" se caracteriza por la profundización de estas contradicciones y su resultado implica la configuración de una tendencia interna que emplea los limites económicos y políticos al proyecto establecido por el pacto "democratizador", inaugurado en 1988. El escenario "poscrisis" tiende a caracterizarse por poner en cuestionamiento al propio proyecto "democratizador", implicando reformas y fuerzas políticas opuestas a este proceso.

\section{REFERENCIAS}

Almeida, J. (2016). Contribuição para entender a crise atual no Brasil. Crítica Marxista, 42, 179-185.

Amin, S. (1974). El Desarrollo Desigual. Ensayo sobre las formaciones sociales del capitalismo periférico. Barcelona: Editorial Fontanella.

Avritzer, L. (2018). O Pêndulo da Democracia no Brasil. Uma análise da crise 2013-2018. Novos Estudos CEBRAP, 37(02), 273-289.

Ayala, R. (2016). Marxismo y Globalización Capitalista. San José: Perro Azul.

Bastos, P. (2012). A economia política do novo-desenvolvimento e do social desenvolvimentismo. Economia e Sociedade, Campinas, 21, Número Especial, 779-810.

Bastos, P. (2017). Ascensão e Crise do Goberno Dilma Rousseff e o golpe de 2016: poder estrutural, contradição e ideologia. Revista Economia Contemporânea, Número Especial, 1-63.

Belluzzo, L., y Almeida, J. (2015). Como recuperar o vigor industrial. Em L. G. Belluzzo, y P. Z. Bastos, Austeridade para quem? Balanço e pespectivas do governo Dilma Rousseff (pp. 27-38). São Paulo: Carta Maior; Friedrich-Ebert-Stiftung.

Bercovici, G. (2010). "O direito constitucional passa, o direito administrativo permanece": a persistência da estrutura administrativa de 1967. Em E. Teles, y V. Safatle, $O$ que resta da ditadura: a exceção brasileira (pp. 77-90). São Paulo: Boitempo.

Boito Jr, A. (2016b). Os atores e o enredo da crise política. Em I. Jinkings, K. Doria, y M. Cleto, Por que gritamos golpe? Para entender o impeachment e a crise pólitica no Brasil (pp. 22-29). São Paulo: Boitempo.

Boito Jr, A. (2016c). A crise política do neodesenvolvimentismo e a instabilidade da democracia. Crítica Marxista, 42, 155-162.

Braga, R. (2016a). La crisis brasileña y el retorno de la lucha de clases. Revista Herramienta, 58. Recuperado de http://www.herramienta.com.ar/revistaherramientan58/ 
Braga, R. (2016b). O fim do lulismo. Em I. Jinkings, K. Doria, y M. Cleto, Por que gritamos golpe?: para entender o impeachment e a crise (pp. 55-60). São Paulo: Boitempo.

Bresser-Pereira, L. (2012). Structuralist Macroeconomics and the New Desenvolvimentism. Brazilian Journal of Political Economy, 32(3) (128), 347-366.

Bresser-Pereira, L. (2016). Reflexões sobre o Novo Desenvolvimentismo e o Desenvolvimentismo Clássico. Revista de Economia Política, 36(2) (143), 237-265.

Carvalho, L. (2018). Valsa brasileira: do boom ao caos económico. São Paulo: Todavia.

Carvalho, L., y Kupfer, D. (2011). Diversificação ou especialização: uma análise do processo de mudança estrutural da indústria brasileira. Revista de Economia Politica 31 (4), 618-637.

Chaui, M. (2016). A nova classe trabalhadora brasileira e a ascensão do conservadorismo. Em I. Jenkings, K. Doria, y M. Cleto, Porque gritamos golpe?: para entender o impeachment e acrise (pp. 15-22). São Paulo: Boitempo.

Coggiola, O. (2015). Impeachment, crise e golpe: o Brasil no palco da tormenta mundial. Blog da Boitempo. Recuperado de https:// blogdaboitempo.com.br/category/colaboracoesespeciais/osvaldo coggiola/

Coggiola, O. (2016). A crise do Brasil capitalista é maior do que a. Blog da Boitempo. Recuperado de https://blogdaboitempo. com.br/category/colaboracoesespeciais/ osvaldo-coggiola/

Diegues, A. (2015). As trasnformações no padrão de organização e acumulação da indústria: da desindustrialização à 'Doencça Brasileira'. Em L. Belluzzo , y P. Bastos, Austeridade para quem? Balanço e pespectivas do governo Dilma Rousseff (pp. 67-74). São Paulo: Carta Maior ; Friedrich Ebert Stiftung.

Fagnani, E. (18/04/2017). Direitos roubados: o fim do breve ciclo de cidadania social no Brasil. Carta Capital. Recuperado de https://www.cartacapital.com.br/politica/ direitosroubadosofimdobreveciclodecidadaniasocialnobrasil
Katz, C. (2016). Neoliberalismo, neodesenvolvimentismo, socialismo. São Paulo: Expressão Popular; Preseu Abramo.

Lapavitsas, C. (2016). Beneficios sin producción. Cómo nos explotan las finanzas. Madrid: Traficante de sueños.

Lavinas, L., y Gentil, D. L. (2018). Brasil anos 2000. A política sob regência da financeirização. Novos Estudos CEBRAP, 37(02), 191-211.

Limongi, F., y Figueiredo, A. (2017). A crise atual e o debate institucional. Novos Estudos. CEBRAP, 109, 79-97.

Marconi, N., y Brancer, M. (2017). A política econômica do novo desenvolvimentismo. Revista de Economia Contemporânea. Numero Especial. Recuperado de http:// dx.doi.org/10.1590/198055272126

Marconi, N., y Oreiro, J. (2016). O Novodesenvolvimentismo e seus críticos. Cadernos do Desenvolvimento, 11(19), 167-179.

Marques, R., y Nakatani, P. (2015). The Strength and Fragility of the Brazilian Economy. Monthly Review, 67(01). Recuperado de http://monthlyreview. org/2015/05/01/thestrengthandfragilityofthebrazilianeconomy/

Martins, C. (2011). Globalização, dependência e neoliberalismo na América Latina. São Paulo: Boitempo.

Marx, C. (1972). El Capital. Crítica de la Economía Política I. México D. F: Fondo de Cultura Económica.

Mattos, F. (2015). A tragédia da desindustrialização no Brasil. Em L. Belluzzo, y P. Bastos, Austeridade para quem? balanço e perspectivas do governo Dilma Rousseff (pp. 75-82). São Paulo: Carta Maior ; Friedrich Ebert Stiftung.

Mussi, D., y Bianchi, A. (2013). É o fim de um ciclo político no Brasil? PUCVIVA 42, 58-61.

Neto, O. (2016). A Crise Política Brasileira de 2015-2016. Diagnóstico, sequelas e profilaxia. Relações Internacionais, 43-54.

Oliveira, F. (2003). Crítica à razão dualista/O ornitorrinco. São Paulo: Boitempo Editorial. 
Oreiro, J. (2012). Novo-desenvolvimentismo, crecimento econômico e regimes de política macroeconômica. Estudos Avançados 26(75), 29-40.

Osorio, J. (2012). El nuevo patrón exportador de especialización productiva en América Latina. Revista Soc. Bras. Economia Politica São Paulo, 31, 31-64.

Paulani, L. (2003). Brasil Delivery: a Política Econômica do Governo Lula. Revista de Economia Política, 23(4) (92), 58-73.

Paulani, L. (2009). A crise do regime de acumulação com dominância da valorização financeira e a situação do Brasil. ESTUDOS AVANÇADOS 23 (66), 25-39.

Paulani, L. (2016). Um ponte para o abismo. Em I. Jinkings, K. Doria, y M. Cleto, Por que gritamos golpe?: para entender o impeachment e a crise (pp. 69-76). São Paulo: Boitempo.

Paulani, L. (2017). Não há saída sem a reversão da financeirização. ESTUDOS AVANÇADOS 31 (89), 29-35.

República Federativa do Brasil. (2017). Constituição da República Federativa do Brasil. Brasília: Câmara dos Deputados, Edições Câmara.

Ribeiro, D. (2015). O povo brasileiro: a formação e o sentido do Brasil. São Paulo: Global.

Rossi, P., y Mello, G. (2016). Componentes Macroeconômicos e Estruturais da Crise Brasileira: o Subdesenvolvimento Revisitado. BRAZILIAN KEYNESIAN REVIEW, 2 (2), 252-263.

Rossi, P., y Mello, G. (2017). Choque recessivo e a maior crise da história: A economia brasileira em marcha à ré. Nota do Cecon, 1. Recuperado de http://brasildebate.com.br/wp-content/uploads/ NotaCecon1_Choque-recessivo-2.pdf

Sampaio Junior, P. (out./dez. 2012). Desenvolvimentismo e neodenvolvimentismo: tragédia e farsa. Serv. Soc. Soc., São Paulo, 112, 672-688.

Semer, M. (2016). Ruptura institucional e desconstrução do modelo democrático: o papel do Judiciário. Em I. Jinkings, K. Doria, y M. Cleto, Por que gritamos golpe?: para entender o impeachment e a crise (pp. 107-114). São Paulo: Boitempo.

Serrano, F., y Summa, R. (2018). Conflito distributivo e o fim da "Breve era de Ouro" da economia Brasileira. Novos Estudos CEBRAP, 37(02), 175-189.

Sicsú, J., De Paula, L., y Michel, R. (2007). Por que novo-desenvolvimentismo? Revista de Economia Política, 27(4), 507-524.

Singer, A. (2009). Raízes sociais e ideológicas do Lulismo. Novos Estudos. CEBRAP 85, 83-102.

Singer, A. (2010). A segunda alma do Partido dos Trabalhadores. Novos Estudos CEBRAP, 88, 89-111.

Singer, A. (2015a). Cutucando onças com varas curtas. $O$ ensaio desenvolvimentista no primeiro mandato de Dilma Rousseff (2011-2014). Novos Estudos 102, 43-71.

Singer, A. (2015b). Quatro notas sobre as classes sociais nos dez anos do lulismo. Psicol. USP 26 (1) São Paulo, 7-14.

Teles, E., y Safatle, V. (2010). O que resta da ditadura: a exceção brasileira. São Paulo: Boitempo.

Touraine, A. (2000). ¿Qué es la democracia? México D.F: Fondo de Cultura Económica.

Zaverucha, J. (2010). Relações civil militares: o legado autoritário da Constituição brasileira de 1988. Em E. Teles, y V. Safatle, $O$ que resta da ditadura: a exceção brasileira (pp. 41-76). São Paulo: Boitempo.

Fecha de ingreso: 04/10/2018

Fecha de aprobación: 08/07/2019 
